\title{
Fatigue-based model for the droplet impingement erosion incubation period of metallic surfaces
}

\author{
Henk Slot ${ }^{1}$, Dave Matthews², Dik Schipper ${ }^{2}$, and Emile Heide ${ }^{2}$ \\ ${ }^{1} \mathrm{TNO}$ \\ ${ }^{2}$ University of Twente
}

June 22, 2020

\begin{abstract}
Droplet impingement of metallic surfaces at high impact velocities results, after some time, in erosion of the surface due to fatigue. By extending our previously published analytical model to enable the use of experimental fatigue data (S-N curves), here, for the first time, a wide range of experimental liquid droplet erosion incubation period test states for both ferrous (stainless steel AISI 316) and non-ferrous (aluminium 6061-T6) engineering metals have been investigated. To achieve this, the developed model includes additional surface hardening and a residual compressive stress state at the surface due to a water drop peening effect. As such, the interrelation of the physical and mechanical properties that follows from the model has been used to identify how changes in selected metal properties might enhance droplet impingement erosion incubation life. Model predictions for both metals, using fatigue data from S-N curves from different literature sources, showed for the droplet impact velocity range of 140 to $400 \mathrm{~m} / \mathrm{s}$ an excellent agreement with results from a multi-regression equation as determined from an ASTM interlaboratory test program.
\end{abstract}

\section{Keywords}

Surface Fatigue, Peening, Surface Hardening, Drop Impact, Predictive Model

\section{Nomenclature}

$A=$ constant in Rayleigh surface wave attenuation $(\mathrm{Pa}[?] \mathrm{m})$ or elongation at fracture $(\%)$

$a=$ material parameter of strain hardening $(1 / \mathrm{Pa})$, or radius of the contact area $(\mathrm{m})$

$b=$ material parameter for the residual stress $(1 / \mathrm{Pa})$

$C_{v}=$ volume concentration of water in air (-)

$c_{l, m}=$ longitudinal wave velocity of metal $(\mathrm{m} / \mathrm{s})$

$c_{R}=$ Rayleigh surface wave velocity in a metal $(\mathrm{m} / \mathrm{s})$

$c_{t}=$ transverse wave velocity of metal $(\mathrm{m} / \mathrm{s})$

$c_{w}=$ speed of sound in water at the pressure $p_{\mathrm{wh}}(\mathrm{m} / \mathrm{s})$

$c_{w 0}=$ speed of sound in water at a pressure of $1 \mathrm{bar}(\mathrm{m} / \mathrm{s})$

$D_{h}=$ cumulative fatigue damage per hour $\left(\mathrm{h}^{-1}\right)$

$D_{f}=$ cumulative fatigue damage at failure (-)

$d_{d}=$ water drop diameter $(\mathrm{m})$ 
$E=$ Young's modulus $(\mathrm{Pa})$

$f=$ fatigue cycle frequency $(\mathrm{Hz})$

$H=$ surface hardness after peening at a certain impact velocity $(\mathrm{Pa})$

$H_{0}=$ material hardness when stress free and without strain hardening $(\mathrm{Pa})$

$h_{\text {tot }}=$ correction factor for the differences between fatigue test and rain impact conditions (-)

$I_{p}=$ droplet impingement erosion incubation period $(\mathrm{h})$

$k=$ constant for the pressure influence on the speed of sound in water (-)

$m=$ material parameter in fatigue tests (-)

$N_{f}=$ fatigue life (number of cycles to failure)

$N_{i}=$ number of fatigue cycles of the incubation period or at level $i(-)$

$N_{0}=$ number of specific impacts for incubation (-)

NOR $=$ incubation resistance number $(-)$

$n=$ number of tests, or exponent for the Rayleigh wave attenuation (-)

$n_{i}=$ number of cycles due to multiple drop impact at stress level $i(-)$

$p_{\mathrm{wh}}=$ water-hammer pressure $(\mathrm{Pa})$

$p_{w h, t h}=$ threshold water-hammer pressure $(\mathrm{Pa})$

$R=$ stress ratio in the fatigue test (-)

$R_{d}=$ maximum erosion rate $(\mathrm{m} / \mathrm{s})$

$R_{e}=$ rationalized erosion rate (-)

$R_{m}=$ tensile strength of metal $(\mathrm{Pa})$

$R_{p 0.2}=$ yield strength of metal $(\mathrm{Pa})$

$r=$ radial coordinate $(\mathrm{m})$

$r_{0}=$ radius of contact area when Rayleigh wave starts $(\mathrm{m})$

$r_{\mathrm{wh}}=$ radius of maximum contact area with the water-hammer pressure $(\mathrm{m})$

$S_{a}=$ stress amplitude $(\mathrm{Pa})$

$S_{D}=$ fatigue limit $(\mathrm{Pa})$

$S_{f}=$ material parameter in fatigue tests $(\mathrm{Pa})$

$S_{f 0}=$ fatigue strength coefficient for stress free metal and without strain hardening $(\mathrm{Pa})$

$S_{m}=$ mean stress $(\mathrm{Pa})$

$S_{\max }=$ maximum stress in a fatigue cycle $(\mathrm{Pa})$

$S_{\max (r 0)}=$ maximum stress due to Rayleigh wave at location $r_{0}(\mathrm{~Pa})$

$s=$ standard deviation $(-)$

$v_{d}=$ water droplet impact velocity on the specimen surface $(\mathrm{m} / \mathrm{s})$

$v_{a}=$ radial velocity of contact area boundary $(\mathrm{m} / \mathrm{s})$ 
$t=$ time $(\mathrm{s})$

$Z=$ reduction of area $(\%)$

$\Phi_{v}=$ volume of impacting water drops per unit area $(\mathrm{m} / \mathrm{s})$

$\nu=$ Poisson constant of metal (-)

$\rho_{m}=$ density of metal $\left(\mathrm{kg} / \mathrm{m}^{3}\right)$

$\rho_{w}=$ density of water $\left(\mathrm{kg} / \mathrm{m}^{3}\right)$

$\sigma_{R}=$ residual (compressive) stress at the surface after peening at a certain impact velocity $(\mathrm{Pa})$

$\frac{V_{\mathrm{water}}}{A_{e}}=$ volume of waterdrops impinged per unit exposed area $(\mathrm{m})$

$\frac{A_{d}}{V_{d}}=$ projected area of a waterdrop divided by the volume of a waterdrop $(1 / \mathrm{m})$

\section{Introduction}

Current research on droplet impingement erosion of metallic surfaces is typically related to the lower pressure stages in steam turbines where the blades suffer from erosion due to the high water content of the steam $^{1-3}$. Another industrial application suffering from droplet impingement erosion is Liquified Natural Gas (LNG) transport. Large LNG drops in a partly evaporated gas are a source of droplet impact erosion of the metallic surfaces of the transfer systems ${ }^{4}$. The blades of large wind turbines also experience droplet impingement erosion, due to impact of rain. The leading edges of wind turbine blades are often protected with polyurethane coatings $^{5,6}$, yet their lifetime is still relatively short. The application of flexible metallic strips to protect the leading edge might therefore become an option, thus illustrating the potential interest in controlling impingement erosion for metallic surfaces.

Droplet impingement of surfaces results, after some time, in erosion of the surface ${ }^{7-9,11-13}$. Recently, work on the modelling of drop impact-induced stresses and related wear, is presented by Slot et al. ${ }^{14,15}$, Amirzadeh et al. ${ }^{16,17}$, and Castorrini et al. ${ }^{18}$, for relatively low impact velocities $(<150 \mathrm{~m} / \mathrm{s})$, for Young's moduli that are representative for polymers and elastomers $(<5 \mathrm{GPa})$ and, more importantly for fully elastic deformation during impact. The physical and metallurgical mechanisms which determine the droplet impingement erosion incubation period $\left(I_{p}\right)$, for metallic surfaces however, are presently not fully understood ${ }^{1-3,5}$. As a result, empirical approaches are used for the assessment of droplet impingement erosion sensitive situations involving metallic surfaces ${ }^{1,4,9,10}$.

The objective of this paper is to identify and understand the physical and metallurgical mechanisms that determine the droplet impingement erosion incubation period for metallic materials. A previously developed fatigue-based model by the authors ${ }^{14,15}$ for droplet impingement erosion of polymeric surfaces is further developed for use of metallic surfaces, given the similarities in general aspects of the erosion process. The extension of the model takes into account fatigue curves of metallic materials, the effect of additional surface hardening and the effect of a residual compressive stress state at the surface due to the "water drop peening effect". The resulting fatigue-based model for the incubation period is tested against the multi-regression fit equation of Heymann ${ }^{10}$ - the current state-of-the-art in estimating the incubation period determined from an ASTM interlaboratory test program, see Appendix A. The developed model is used for metallic surfaces in general and includes data taken from literature for stainless steel AISI 316 and aluminium 6061-T6. By quantifying the interrelation of the physical degradation mechanisms and the mechanical properties of the metals guidelines can be given for metallic surfaces with respect to droplet impingement erosion life.

\section{Modelling}

\subsection{Stress cycle due to drop impact}

The main building blocks of the existing model that is described in detail in ${ }^{14,15}$ are the water -hammer pressure, which originates from compression of the liquid on impact of the surface, see Figure 1 and the 
resulting stress cycle from the Rayleigh wave. The water-hammer pressure $p_{\mathrm{wh}}$ is given by ${ }^{14,22}$ :

$$
\begin{gathered}
p_{\mathrm{wh}}=v_{d} \frac{\rho_{w} c_{w}}{\left(\frac{\rho_{w} c_{w}}{\rho_{m} c_{l, m}}+1\right)} \\
c_{w}=c_{w 0}+k v_{d}
\end{gathered}
$$

$v_{d}=$ drop impact velocity,

$\rho_{w}=$ density of water at 1 bar, $1000 \mathrm{~kg} / \mathrm{m}^{3}$,

$c_{w}=$ speed of sound in water at the pressure $p_{\mathrm{wh}}$,

$c_{w 0}=$ speed of sound in water at a pressure of $1 \mathrm{bar}, 1647 \mathrm{~m} / \mathrm{s}$,

$k=$ constant for the pressure influence on the speed of sound ${ }^{22}, 1.921$,

$\rho_{m}=$ density of metal,

$c_{l, m}=$ longitudinal wave velocity of metal.

Due to the impact and the assumed round shape of the droplet, the initial velocity of the boundary of the contact area with the solid surface is infinitely high. This velocity $v_{a}$ decreases rapidly to respectively the longitudinal wave velocity $\left(c_{l, m}\right)$, the transverse wave velocity $\left(c_{t}\right)$, the Rayleigh wave velocity $\left(c_{R}\right)$, and finally to the speed of sound in water for this compressed state $\left(c_{w}\right.$, see Eq. 1). When $v_{a}<c_{w}$ the compressed water volume losses its high pressure $\left(p_{\mathrm{wh}}\right)$.

The radius of the contact area ( $a$ ) of the droplet with the rigid surface as a function of time $(t)^{23}$ is described by:

$$
a=\sqrt{\left(2 R_{d} v_{d} t-\left(v_{d} t\right)^{2}\right)}
$$

The radial velocity of this contact area boundary $\left(v_{a}\right)$ is defined by:

$$
v_{a}=\frac{\mathrm{da}}{\mathrm{dt}}=\frac{\left(R_{d} v_{d}-v_{d}^{2} t\right)}{\sqrt{\left(2 R_{d} v_{d} t-\left(v_{d} t\right)^{2}\right)}}
$$

With

$$
R_{d}=\frac{d_{d}}{2}
$$

At the time when the surface Rayleigh wave starts $v_{a}$ equals $\mathrm{c}_{\mathrm{R}}$ and the radius of the contact area $\left(r_{0}\right)$ reads:

$$
r_{0}=\frac{d_{d} c_{R}}{2 v_{d}}\left\{\sqrt{1+2\left(\frac{v_{d}}{c_{R}}\right)^{2}}-1\right\}
$$


The compressed water volume loses its high pressure when the velocity of its contact area boundary decreases to the speed of sound in water for this compressed state, $c_{w}$. The maximum contact area for which the waterhammer pressure acts follows from the condition: $v_{a}=c_{w}$. Replacing $c_{R}$ by $c_{w}$ in Eq. 4 and using Eq. 1b gives the related contact radius $\left(r_{\mathrm{wh}}\right)$ :

$$
r_{\mathrm{wh}}=\frac{d_{d}\left(c_{w 0}+k v_{d}\right)}{2 v_{d}}\left\{\sqrt{1+2\left(\frac{v_{d}}{c_{w 0}+k v_{d}}\right)^{2}}-1\right\}
$$

In this work, it is chosen to select one droplet diameter for all model predictions, while the impact velocity is varied. A droplet diameter $d_{d}=1.8 \mathrm{~mm}$ serves as representative value, within the presented range by Heymann ${ }^{10}$ of 1.2 to $2.0 \mathrm{~mm}$. The drop impact velocities are taken equal to 140,210 and $400 \mathrm{~m} / \mathrm{s}$, similar to the experimental work that is used by Heymann ${ }^{10}$.

For this droplet diameter, the impact velocities result for AISI 316 in contact radii $\left(r_{0}\right)$ of respectively 0.04 , 0.07 and $0.13 \mathrm{~mm}$, and radii $\left(r_{\mathrm{wh}}\right)$ of respectively $0.07,0.09$ and $0.15 \mathrm{~mm}$.

The water-hammer pressure $\left(p_{\text {wh }}\right)$ gives rise to cyclic stresses $(S)$. Cyclic stresses are well known to cause fatigue, in this case surface fatigue. The maximum stress of this cycle due to the Rayleigh surface wave can be given by ${ }^{14}$ :

$$
S_{\max }=\frac{A}{r^{n}}
$$

In which $A$ depends on the water-hammer pressure $\left(p_{\mathrm{wh}}\right), n$ is a constant and $r$ is the radial coordinate. By assuming that the stress cycle starts at $r=r_{0}$ (see Eq. 4) and is attenuated at $r=r_{1}$ at a maximum stress level $S_{\max }=S_{\max , 1}$, which is equal to the fatigue limit after which no further fatigue damage occurs, the stress cycle is known. The value $A$ in Eq. 6 is determined by Slot et al. ${ }^{14,15}$ for $d_{d}=1.8 \mathrm{~mm}$ and $n=0.5$, and reads:

$$
A=0.60 p_{\mathrm{wh}} \quad\left(d_{d}=1.8 \mathrm{~mm}\right)
$$

\subsection{Fatigue life model for metallic surfaces that includes strain hardening and shot peening}

Applying a general expression for fatigue life for a stress level $i$ to the case of drop impact results in Eq. 8a, introducing $h_{\text {tot }}$ that corrects for the differences between the fatigue test conditions and the actual conditions. The constants $m$ and $S_{f}$ are commonly used material parameters in fatigue tests:

$S_{\text {max }, i}=h_{\mathrm{tot}} S_{f} N_{i}^{-1 / m}$

The fatigue limit $S_{D, i}$ for the actual erosion conditions is given by:

$$
S_{D, i}=h_{\mathrm{tot}} S_{D}
$$

In this approach, the number of fatigue cycles to failure in a fatigue test $\left(N_{f}\right)$ equals the number of fatigue cycles of the incubation period $\left(N_{i}\right)$.

For metals showing strain hardening, the effects of additional surface hardening and the related residual compressive stress state at the surface due to the "water drop peening effect" should be included as it will 
affect the fatigue life. The well-known Morrow's equation with mean stress correction ${ }^{24}$ can be used for this purpose. In the present case the modified version as derived by Landgraf et al. ${ }^{25}$ is used:

$$
\frac{S_{a}}{\left(\frac{H}{H_{0}} S_{f, 0}-S_{m}-\sigma_{R}\right)}=\left(2 N_{f}\right)^{-\left(\frac{1}{m}\right)}
$$

With:

$S_{a}=$ stress amplitude,

$S_{m}=$ mean stress,

$\frac{H}{H_{0}}=$ ratio of increased surface hardness to initial surface hardness,

$\sigma_{R}=$ residual stress at the metal surface

$N_{f}=$ fatigue life (number of cycles to failure)

$S_{f, 0}=$ fatigue strength coefficient of metal with initial hardness $H_{0}$, mean stress $S_{m}=0$ (or $R=-1$ ), and residual stress $\sigma_{R}=0$,

$R=$ stress ratio, ratio of minimum stress and maximum stress.

The fatigue strength coefficient $\left(S_{f}\right)$ in Eq. 8a is to be determined for a stress ratio of $R=-0.5$, given by the Rayleigh wave amplitudes ${ }^{14}$. Using Eq. 9 and assuming that the fatigue curves are available for a stress ratio $\mathrm{R}=-1$ (the definition used for $S_{f, 0}$ ), the following expression for fatigue strength coefficient $S_{f}$ in Eq. 8a (with $R=-0.5$ ) was derived:

$$
S_{f}=\left(1+\frac{1+R}{1-R}\right)\left(\frac{H}{H_{0}} \cdot \frac{S_{f, 0}}{2^{-\left(\frac{1}{m}\right)}}-\sigma_{R}\right) 2^{-\left(\frac{1}{m}\right)}
$$

Eq. 10 now includes the (possible beneficial) effect of surface hardening and residual stress. It is assumed in this work that this beneficial effect occurs relative to the 'water -hammer pressure' $\left(p_{\mathrm{wh}}\right)$, see Eq. 1a, and the maximum loaded surface area with a contact radius $\left(r_{\text {wh }}\right)$, see Eq. 5. By using a threshold water-hammer pressure $\left(p_{w h, t h}\right)$, above which surface hardness and residual compressive stresses increase, it was possible to construct the following model.

- if $p_{\mathrm{wh}}>p_{w h, t h}$ :

$$
\begin{gathered}
\frac{H}{H_{0}}=1+a\left(p_{\mathrm{wh}}-p_{w h, t h}\right) \\
\sigma_{R}=b\left(p_{\mathrm{wh}}-p_{w h, t h}\right)
\end{gathered}
$$

- if $p_{\mathrm{wh}} \leq p_{w h, t h}$ :

$$
\begin{aligned}
\frac{H}{H_{0}} & =1.0 \\
\sigma_{R} & =0
\end{aligned}
$$

$p_{w h, t h}=$ threshold water-hammer pressure,

$a, b=$ material dependent constants, see Table B-2 of Appendix B. 
Similar to the work described in detail ${ }^{15}$ one can use the Palmgren-Miner rule to account for the cumulative fatigue damage at different stress levels. The basic form of this equation for variable amplitude stress loading is:

$$
D=\sum_{i=1}^{k} \frac{n_{i}}{N_{i}}
$$

In which $n_{i}=$ number of cycles due to multiple drop impact at stress level $i$.

The droplet erosion incubation period is now defined as:

$$
I_{p}=\frac{D_{f}}{D_{h}}
$$

$I_{p}=$ Droplet erosion incubation period $(\mathrm{h})$

$D_{f}=$ Cumulative fatigue damage at failure

$D_{h}=$ Cumulative fatigue damage per hour $\left(\mathrm{h}^{-1}\right)$

According to the general Palmgren-Miner approach ${ }^{14,15}: D_{f}=1$. Using this approach a fatigue-based model for the droplet impingement erosion incubation period of metallic surfaces can be formulated. An expression for the incubation period can be derived ${ }^{15}$ :

$$
\begin{gathered}
I_{p}=\frac{d_{d}^{3}}{24 \Phi_{v}} \frac{(m-4)\left(h_{\mathrm{tot}} S_{f}\right)^{m}}{A^{4}} \frac{1}{\left[S_{\max (r 0)}^{(m-4)}-\left(h_{\mathrm{tot}} S_{D}\right)^{(m-4)}\right]} \\
\Phi_{v}=3.6 \times 10^{6} \mathrm{C}_{v} v_{d}
\end{gathered}
$$

In which:

$\Phi_{v}=$ volume of impacting water drops per unit area $(\mathrm{mm} / \mathrm{h})$

With $S_{\max (r 0)}$ according to Eq. 6 and using $r_{0}$ according to Eq. 4.

Furthermore $S_{\max (r 0)}>h_{\mathrm{tot}} S_{D}$ and for the complementary condition $S_{\max (r 0)} \leq h_{\mathrm{tot}} S_{D}$ this results in: $I_{p} \rightarrow \infty$. Thus the condition $S_{\max (r 0)}=h_{\text {tot }} S_{D}$ gives the threshold drop impact velocity $\left(v_{d, t h}\right)$. For drop impact conditions $\left(v_{d}, d_{d}\right)$ resulting $\operatorname{in} S_{\max (r 0)} \leq h_{\text {tot }} S_{D}$, the fatigue damage will not accumulate to fatigue failure and thus the life of the metal surface will be infinite.

\section{Results for stainless steel AISI 316 and aluminium 6061-T6}

The droplet impingement incubation period was predicted for stainless steel AISI 316 and aluminium 6061-T6 using the presented analytical model and the fatigue life curves in Table B-1, and including the additional surface hardening and residual compressive stress at the surface due to the "water drop peening effect" with the data derived in Appendix B that is summarised in Table B-2. For $h_{\text {tot }}$, a value of 1 was taken, this assuming that there are no corrections necessary for the differences between the fatigue test conditions and the actual droplet impingement erosion test conditions. Figures 2 and 3 show the predicted curves in comparison to the incubation periods and confidence limits according to the multi-regression equation of Heymann ${ }^{10}$, Eq. A-1 as given in Appendix A.

The Figures show that these predicted incubation periods are nearly all within the 2.5 and $97.5 \%$ confidence limits of the multi-regression equation for the given metal. These limits of the multi-regression equation are partly a result of experimental uncertainty and partly due to differences between used test set-ups ${ }^{10}$. 


\section{Discussion}

The model predictions for stainless steel AISI 316 and aluminium 6061-T6 showed an excellent agreement with the multi-regression equation of Heymann ${ }^{10}$ that is determined from an ASTM interlaboratory test program. Nearly all incubation period predictions were within the $95 \%$ confidence limits of the mentioned multi-regression equation.

An essential aspect of the current model is the fatigue-based approach in which now the surface hardening and residual compressive stress effects caused by the impact of the droplets are taken into account as well. The value for the threshold water-hammer pressure $\left(p_{w h, t h}\right)$, which is used in the Eq. 11a and 11b, is based on the extensive research by Thiruvengadam et al. ${ }^{43-45}$.

They performed water jet impact erosion tests with metals in a high speed rotating disk facility. Observation of the specimens to determine when denting or erosion occurred was implemented in the test sequence. Depending on the impact velocity, the specimens were microscopically inspected at intervals ranging from every few minutes to every hour. The number of impacts taken for the initiation of permanent plastic indentations on the surface was recorded at different test velocities. Results for stainless steel AISI 316 (cold drawn), and aluminium 1100-O, as a function of the impact velocity are shown in Figures 4a and b. The number of impacts necessary for observing a small permanent plastic dent is a clear function of the impact velocity.

This number of impacts varies for stainless steel AISI 316 (cold drawn), in the velocity range $70-100 \mathrm{~m} / \mathrm{s}$, between 2 to $5 \%$ of the incubation period. For aluminium 1100-O, this number of impacts varies, in the velocity range $40-60 \mathrm{~m} / \mathrm{s}$, also between 2 to $5 \%$ of the incubation period.

Thus it is concluded that permanent plastic indentations in the surface of these metals are present during $95-98 \%$ of the incubation period $\left(I_{p}\right)$. In this period a form of liquid impact peening of the metal surface gives rise to an additional surface hardening and a residual compressive stress state at the surface.

It is assumed in this work that this beneficial effect occurs relative to the 'water -hammer pressure' $\left(p_{\text {wh }}\right)$, see Eq. 1a, and the maximum loaded surface area with a contact radius $\left(r_{\mathrm{wh}}\right)$, see Eq. 5 , are the parameters which govern the beneficial effects of residual compressive stress and increase in surface hardness, at a certain impact velocity.

The incorporated effect of surface hardening and residual compressive stress for AISI 316 and aluminium 6061-T6 on fatigue strength can be substantiated based on evidence from literature. Soyama ${ }^{46}$ compares $^{2}$ the improvements made to the fatigue strength of stainless steel AISI 316L by cavitation peening, water jet peening, shot peening and laser peening. For each peening method, the optimum coverage was examined by measuring the fatigue life at constant bending stress. The fatigue strength of the non-peened specimen was $280 \mathrm{MPa}$. For the treated samples the increase was: $25 \%$ for cavitation peening, $16 \%$ for shot peening, $9 \%$ for laser peening and $6 \%$ for water jet peening. Cho ${ }^{48}$ performed FEM simulations of the repeated waterdrop impact, drop size of $0.2 \mathrm{~mm}$, on 6061-T6 aluminium. In this computational study, residual effects of repeated waterdrop impact onto an aluminium surface were investigated. The results show that above a critical impact velocity $(74 \mathrm{~m} / \mathrm{s})$, a residual compressive stress zone is built up under the impact surface as a result of local plastic deformation. The depth of the plastic deformation increases with the impact velocity and number of impacts. At an impact speed of $500 \mathrm{~m} / \mathrm{s}$, after 4 impacts, the maximum residual compressive stress is $-345 \mathrm{MPa}\left(-1.06 \mathrm{R}_{\mathrm{p} 0.2}\right)$ and is obtained at $0.07 \mathrm{~mm}$ under the surface, and the depth of the compressive stress zone is $0.2 \mathrm{~mm}$. Rajesh ${ }^{49,50}$ performed multi-droplet impact FE-modelling to predict the residual stresses due to water jet peening for three grades of aluminium. For this modelling approach, a transient elastoplastic finite element analysis is used by considering the impingement of a set of droplets in succession to one another over a certain time period. The pressure is released following this sequence. For aluminium 6063-T6 $\left(\mathrm{R}_{\mathrm{p} 0.2}=110 \mathrm{MPa}\right)$, for drop impact speeds between 532 and $604 \mathrm{~m} / \mathrm{s}$, and applying 1 to 4 "layers" of water drops this was found to result in compressive stresses between $-0.36 R_{\mathrm{p} 0.2}$ and $-0.61 R_{\mathrm{p} 0.2}$ at the impacted surface. These results ${ }^{46-50}$ clearly confirm that for appropriate water drop impact conditions, residual compressive stresses and an increase in surface hardness due to strain hardening occur. 
In the current work, an analytical model for the prediction of the droplet impingement erosion incubation period of metal surfaces is presented. The model is based on the $\mathrm{S}-\mathrm{N}$ curve of the metal, on the effects of additional surface hardening and residual compressive stress at the surface due to a "water drop peening effect", such as demonstrated for the case of Al 6061-T6 and AISI 316. Application of the model to other metals requires the steps as shown in the flow diagram in Figure 5.

The presented analytical model gives the interrelation of the physical and mechanical properties of the metallic surfaces that determines the droplet impingement erosion incubation period. As such, it becomes possible to define guidelines for a longer droplet impingement erosion incubation life based on optimised physical and mechanical properties. Selected properties of the metals used in the presented analytical model are summarised in Table 1. The required direction of the property ( - : increase, and - : decrease) for an optimal long droplet impingement erosion incubation life is indicated. From Table 1 it follows that a higher fatigue strength affects the incubation period positively. Using the corresponding equations shows that for instance an increase in the fatigue strength coefficient $\left(S_{f, 0}\right)$ of AISI 316 with $10 \%$, and using $\mathrm{m}=7.8$, the average value for AISI 316 in Table B-2, results, with Eqs. 10 and 14, in an increase in the incubation period $\left(I_{p}\right)$ with a factor of 2.1 .

\section{Conclusions}

The following conclusions are drawn:

1. In the current paper a fatigue based analytical model for the prediction of the droplet impingement erosion incubation period of metal surfaces loaded by impacting water drops published by authors (Slot et al. ${ }^{15}$ ), was tested against a wide range of liquid droplet erosion incubation period tests. The model was extended for the use of S-N curves for aluminium and stainless steel, by including the effects of additional surface hardening and residual compressive stress at the surface due to a water drop peening effect.

2. The model predictions for stainless steel AISI 316 and aluminium 6061-T6, using S-N fatigue curves from different literature sources, see Table B-1, and including the defined additional surface hardening and a residual compressive stress state at the surface due to "water drop peening effect", showed for the droplet impact velocity range of 140 to $400 \mathrm{~m} / \mathrm{s}$ an excellent agreement with the multi-regression equation as determined from an ASTM interlaboratory test program. Nearly all incubation period predictions were within the $95 \%$ confidence limits of the mentioned multi-regression equation.

3. The physical and metallurgical mechanisms resulting in the degradation process of the metal surface during the incubation period $\left(I_{p}\right)$ were identified, these consisted of: 1) surface plastic deformation and, formation of dents, 2) surface hardening and residual compressive stress as a result of these surface plastic deformations, 3) fatigue crack initiation, 4) short fatigue crack growth.

4. Selected properties of metals used in the presented analytical model were identified with respect to the direction it should be adjusted for enhanced droplet impingement erosion incubation life.

\section{References}

[1] Ahmad M, Schatz M, Casey MV. An empirical approach to predict droplet impact erosion in low-pressure stages of steam turbines. Wear 2018;402/403: 57-63.

[2] Kirols HS, Kevorkov D, Uihlein A, Medraj M. Water droplet erosion of stainless steel steam turbine blades. Materials Research Express 2017;4: 1-12.

[3] Ilieva GI. Erosion failure mechanisms in turbine stage with twisted rotor blade. Engineering Failure Analysis 2016;70: 90-104.

[4] DNVGL, LNG - N 2 Stripper inlet pipe - Velocity limitation. Report No.: 2016-0290, 2016.

[5] Bartolomé L, Teuwen J. Prospective challenges in the experimentation of the rain erosion on the leading edge of wind turbine blades. Wind Energy 2019;22: 140-151. 
[6] Gohardani O. Impact of erosion testing aspects on current and future flight conditions. Progress in Aerospace Sciences 2011;47: 280-303.

[7] Thiruvengadam A, Heymann FJ, eds. Characterization and Determination of Erosion Resistance. ASTM STP 474, USA: ASTM International; 1970.

[8] Thiruvengadam A, eds. Erosion, Wear, and Interfaces with Corrosion. ASTM STP 567, USA: ASTM International; 1974.

[9] Heymann FJ, Toward Quantitative Prediction of Liquid Impact Erosion, In: Thiruvengadam A, Heymann FJ, eds. Characterization and Determination of Erosion Resistance. ASTM STP 474, USA: ASTM International; 1970: 212-248.

[10] Heymann FJ. Conclusions from the ASTM Interlaboratory Test Program with Liquid Impact Erosion Facilities. In: Field JE, eds. Proceedings of the Fifth International Conference on Erosion by Liquid and Solid Impact (ELSI-V). Cambridge: Cavendish Laboratory; 1979: paper 20, 1-10.

[11] Schmitt Jr. GF. Liquid and Solid Particle Impact Erosion. In: Peterson MB, Winer WO, eds. Wear Control Handbook. American Society of Mechanical Engineers; 1980.

[12] Heymann FJ. Liquid Impingement Erosion. In: ASM Handbook, Friction, Wear and Lubrication, vol. 18. ASM International; 1998.

[13] ASTM-G73-2010. Standard Practice for Liquid Impingement Erosion Testing. USA:American Society for Testing and Materials; 2010.

[14] Slot HM, Gelinck ERM, Rentrop C, Heide E van der. Leading edge erosion of coated wind turbine blades: Review of coating life models. Renewable Energy 2015;80: 837-848.

[15] Slot HM, IJzerman RM, Feber M le, Heide E van der. Rain erosion resistance of injection moulded and compression moulded polybutylene terephthalate PBT. Wear 2018;414/415: 234-242.

[16] Amirzadeh B, Louhghalam A, Raessi M, Tootkaboni M. A computational framework for the analysis of rain-induced erosion in wind turbine blades, part I: Stochastic rain texture model and drop impact simulations. Journal of Wind Engineering \& Industrial Aerodynamics 2017;163: 33-43.

[17] Amirzadeh B, Louhghalam A, Raessi M, Tootkaboni M. A computational framework for the analysis of rain-induced erosion in wind turbine blades, part II: Drop impact-induced stresses and blade coating fatigue life. Journal of Wind Engineering \& Industrial Aerodynamics 2017;163: 44-54.

[18] Castorrini A, Corsini A, Rispoli F, Venturini P, Takizawa K, Tezduyar TE. Computational analysis of wind-turbine blade rain erosion. Computers and Fluids 2016;141: 175-183.

[19] Solomon N, Solomon I. Deformation induced martensite in AISI 316 stainless steel. Revista de Metalurgia 2010; 46: 121-128.

[20] Deloro Stellite Inc. Wrought Wear-Resistant Alloys Stelliteß 6B \& Stellite® 6K - Plate, Sheet and Bar. Brochure, www.stellite.com; 2008.

[21] Polmear I, StJohn D, Nie J-F, Qian M. Light Alloys: Metallurgy of the Light Metals. Oxford: Butterworth-Heinemann; 2017.

[22] Heymann FJ. On the Shock Wave Velocity and Impact Pressure in High-Speed Liquid-Solid Impact. J. Basic Eng. 1968;90: 400-402.

[23] Adler WF. Liquid drop collisions on deformable media. Journal of Materials Science 1977;12: 1253-1271.

[24] Morrow J. Fatigue Design Handbook - Advances in Engineering. SAE-AE-4. Warrendale (PA): Society of Automotive Engineers; 1968: 21-29. 
[25] Landgraf RW, Chernenkoff RA, Residual Stress Effects on Fatigue of Surface Processed Steels, In: Champoux RL, Kapp JA, Underwood JH, eds. Analytical and Experimental Methods for Residual Stress Effects in Fatigue. ASTM STP 1004. ASTM International; 1988: 1-12.

[26] Tokaji K, Kohyama K, Akita M. Fatigue behaviour and fracture mechanism of a 316 stainless steel hardened by carburizing. International Journal of Fatigue 2004;26: 543-551.

[27] Kamaya M, Kawakubo M. Fatigue life prediction of stainless steel under variable loading. Journal of the Society of Materials Science (Japan) 2011;60: 871-878.

[28] Herrera-Solaz V, Niffenegger M. Application of hysteresis energy criterion in a microstructure-based model for fatigue crack initiation and evolution in austenitic stainless steel. International Journal of Fatigue 2017; 100: 84-93.

[29] Maruyama N, Mori D, Hiromoto S, Kanazawa K, Nakamura M. Fatigue strength of 316L-type stainless steel in simulated body fluids. Corrosion Science 2011;53: 2222-2227.

[30] Leeuwen JFC van. Het vermoeiingsgedrag van Roestvast staal. MSc thesis, Delft: TNO, 1995.

[31] Liljas M, Ericsson C. Fatigue behaviour of stainless steel welds. ACOM 1/2, Sweden: Avesta-Polarit; 2002 .

[32] Mohammad KA, Ali A, Sahari BB, Abdullah S. Fatigue behavior of Austenitic Type 316L Stainless Steel. IOP Conf. Series: Materials Science and Engineering 2012: 36 (012012): 1-9.

[33] Rama Krishna L, Madhavi Y, Sahithi T, Wasekar NP, Chavan NM, Srinivasa Rao D. Influence of prior shot peening variables on the fatigue life of micro arc oxidation coated 6061-T6 Al alloy. International Journal of Fatigue 2018;106: 165-174.

[34] Wasekar NP, Jyothirmayi A, Sundararajan G, Influence of prior corrosion on the high cycle fatigue behavior of microarc oxidation coated 6061-T6 Aluminum alloy. International Journal of Fatigue 2011;33 $1268-1276$.

[35] Takahashi Y, Shikama T, Yoshihara S, Aiura T, Noguchi H. Study on dominant mechanism of highcycle fatigue life in 6061-T6 aluminum alloy through microanalyses of microstructurally small cracks, Acta Materialia 2012;60: 2554-2567.

[36] Scott-Emuakpor O, George T, Cross C, Herman Shen M-H. Hysteresis-loop representation for strain energy calculation and fatigue assessment. Journal of Strain Analysis for Engineering Design 2010;45: 275282.

[37] Mutombo K, Toit M du. Corrosion fatigue behaviour of aluminium alloy 6061-T651 welded using fully automatic gas metal arc welding and ER5183 filler alloy. International Journal of Fatigue 2011;33: 1539-1547.

[38] ASM Handbook, Properties and Selection: Irons, Steels, and High-Performance Alloys, Vol. 1. ASM International; 1998.

[39] Masaki K, Ochi Y, Matsumura T. Initiation and propagation behaviour of fatigue cracks in hard-shot peened Type 316L steel in high cycle fatigue. Fatigue Fract Eng Mater Struct. 2004;27: 1137-1145.

[40] Gariepy A, Miao HY, Levesque M. Simulation of the shot peening process with variable shot diameters and impacting velocities. Advances in Engineering Software 2017;114: 121-133.

[41] Hirai N, Tosha K, Rouhaud E. Finite element analysis of shot peening - on the form of a single dent. In: Proc 9th conf shot peening (ICSP9) 2005: 82-87.

[42] Mylonas GI, Labeas G. Numerical modelling of shot peening process and corresponding products: residual stress, surface roughness and cold work prediction. Surface and Coatings Technology. 2011;205: 44804494 . 
[43] Thiruvengadam A, Rudy SL. Experimental and Analytical Investigations on Multiple Liquid Impact Erosion. Report of Hydronautics Inc., NASA-CR-1288; 1969.

[44] Thiruvengadam A, Rudy SL, Gunasekaran M. Experimental and Analytical Investigations on Multiple Liquid Impact Erosion. Report of Hydronautics Inc., NASA-CR-1638; 1970.

[45] Thiruvengadam A, Rudy SL, Gunasekaran M. Experimental and Analytical Investigations on Liquid Impact Erosion. In: Characterization and Determination of Erosion Resistance - ASTM STP 474. ASTM International; 1970: 249-280.

[46] Soyama H. Comparison between the improvements made to the fatigue strength of stainless steel by cavitation peening, water jet peening, shot peening and laser peening. Journal of Materials Processing Technology 2019;269: 65-78.

[47] Ramulu M, Kunaporn S, Jenkins M, Hashish M, Hopkins J. Fatigue Performance of High-Pressure Waterjet-Peened Aluminum Alloy. Journal of Pressure Vessel (ASME) 2002;124: 118-123.

[48] Cho JR. Simulation of the repeated waterdrop impact onto the Al6061-T6. Journal of Mechanical Science and Technology 2015;29: 3679-3683.

[49] Rajesh N, Veeraraghavan S, Ramesh Babu N. A novel approach for modelling of water jet peening. International Journal of Machine Tools \& Manufacture 2004;44: 855-863.

[50] Rajesh N, Ramesh Babu N. Multi-droplet Impact Model for Prediction of Residual Stresses in Water Jet Peening of Materials. Materials and Manufacturing Processes 2006;21: 399-409.

\section{Appendix A - ASTM Interlaboratory test program with liquid impact erosion facilities}

\section{A.1 ASTM - Multiple linear regression fit equations}

Based on an extensive international test program with liquid impact erosion facilities at different research organisations and universities, and sponsored by ASTM, Heymann ${ }^{9,10}$ derived a multiple linear regression fit equation for the incubation life. He presented the following equation for the incubation period as a function of impingement conditions of waterdrops and metal surface grade:

$$
\log N_{0}=-5.64 \log v_{d}-3.12 \log d_{d}+\log \mathrm{NOR}+18.94 \quad(s=0.21, n=31)
$$

With

$N_{0}=$ "number of specific impacts" for incubation (-),

$v_{d}=$ impact velocity normal to the target surface $(\mathrm{m} / \mathrm{s})$,

$d_{d}=$ waterdrop diameter $(\mathrm{mm})$.

NOR = "incubation resistance number" as defined by Heymann ${ }^{9,10}$. This is a normalized resistance value for a certain metal surface grade with respect to stainless steel AISI $316(\mathrm{NOR}=1)$ with a hardness of 170 Vickers.

Eq. A-1 is a multi-regression fit equation for results of droplet impingement erosion tests performed with erosion test facilities at ten laboratories. All of these have facilities of the type where one or more specimens are attached to a rotating disc or arm and their circular path intersects one or more liquid sprays. The drop impact velocity is taken as the peripheral velocity of the specimen. The tests are performed at drop impact velocities of 140,210 , and $400 \mathrm{~m} / \mathrm{s}$, the drop sizes ranges from 1.2 to $2.0 \mathrm{~mm}$.

For stainless steel AISI $316(\mathrm{NOR}=1)$ and a drop size of $1.8 \mathrm{~mm}$, this multi-regression fit equation (Eq. A-1) results to thenumber of specific impacts for incubation as a function of water drop impact velocity as shown in Figure A-1. The 2.5 and $97.5 \%$ confidence limits of the log-normal distribution are given. The used nominal drop impact velocities in the interlaboratory test program are also shown. 
The number of specific impacts for incubation can be transformed to incubation period in hours by using the definition for "number of specific impacts" is given by ${ }^{9,10}$ :

$$
N_{0}=\left(\frac{V_{\text {water }}}{A_{e}}\right) \times\left(\frac{A_{d}}{V_{d}}\right)=3600 C_{v} v_{d} I_{p} \times \frac{3000}{2 d_{d}}=5.4 \times 10^{6} \frac{C_{v} v_{d} I_{p}}{d_{d}}
$$

$\frac{V_{\text {water }}}{A_{e}}=$ volume of waterdrops impinged per unit exposed area

$\frac{A_{d}}{V_{d}}=$ projected area of a waterdrop divided by the volume of a waterdrop

$C_{v}=$ volume concentration of water in air (-)

$I_{p}=$ incubation period $(\mathrm{h})$

In the whirling arm tests used by Heymann ${ }^{9,10}$, the mean volume concentration of water in air, $C_{v}=1.8 \mathrm{x}$ $10^{-6}$ (mean $\log \left(C_{v}\right)=-5.74$, standard deviation $\mathrm{s}=0.44$ ). By way of comparison: for typical rain conditions, rain intensity $\mathrm{I}_{\mathrm{r}}=25.4 \mathrm{~mm} / \mathrm{h}$, drop size $\mathrm{d}_{\mathrm{d}}=1.8 \mathrm{~mm}$, and gravitational drop velocity $\mathrm{v}_{\mathrm{g}}=6.2 \mathrm{~m} / \mathrm{s}^{6}$, the volume concentration of water in air, $C_{v}=1.1 \times 10^{-6}\left(\log \left(C_{v}\right)=-5.94\right)$.

The metals supplied to the laboratories are: Aluminium 1100-O and 6061-T6, Nickel 270, Stainless Steel AISI 316, and Stellite 6B. The first four metals provided most of the test data; only a few data-points are included for Stellite 6B. The normalized "incubation resistance numbers" (NOR) are determined for each of the metals tested, the numbers are shown in Table A-1. All relevant differences in metal properties compared to AISI 316 (hardness of $170 \mathrm{HV}$ ) are accumulated in the NOR value of the metal.

\section{A.2 Properties of metals in ASTM test program}

The mechanical properties of the metals used in the ASTM Interlaboratory test program ${ }^{10}$ are summarized in Table A-2. For all metals, with the exception of Stellite $6 \mathrm{~B}$, specimens manufactured from sheet and rod have been used in the erosion tests. For stainless steel AISI 316 hardness values ranging from 153 to $205 \mathrm{HV}$ (Hardness Vickers) have been used. The measured incubation periods of AISI 316 have been corrected with a special procedure ${ }^{9}$ to a hardness of $170 \mathrm{HV}$.

Austenitic stainless steel AISI 316 contains (in wt\%) 17Cr-10Ni-2Mo-0.02-0.04C with a thermodynamically stable austenite structure ${ }^{19}$. Stellite $6 \mathrm{~B} \mathbb{R}$ is a Co-alloy containing (in wt\%) $28 \mathrm{Cr}, 4.5 \mathrm{~W}$, and $1.1 \mathrm{C}$, and normally supplied as mill-annealed sheet ${ }^{20}$. Aluminium 6061-T6 is an Al-Mg-Si alloy which has been heat treated for precipitation hardening. Aluminium $1100-\mathrm{O}$ is an unalloyed annealed soft aluminium ${ }^{21}$.

\section{Appendix B - Fatigue properties of AISI 316 and Al-6061-T6}

Fatigue properties of stainless steel AISI 316(L) and aluminium 6061-T6 as used in the ASTM Interlaboratory test program were collected from literature ${ }^{26-37}$, see Table B-1. These references show a substantial amount of test data, so a S-N curve could be fitted and a fatigue limit at 2 million cycles could be determined. The stress ratios of these fatigue data were $R=0.1$ or -1 . Fatigue data with a stress ratio $R=0.1$ were corrected to $R=-1$ (mean $\operatorname{stress}_{m}=0$ ) using Morrow's equation ${ }^{24}$ for a mean stress correction, see Eq. 9. The collected fatigue data are summarized in Table B-1.

The physical properties for stainless steel AISI 316(L) and Al-6061-T6 were collected from the Metals handbook $^{38}$. For AISI $316(\mathrm{~L})$ : density $\rho=8000 \mathrm{~kg} / \mathrm{m}^{3}$, Young's modulus, $\mathrm{E}=193 \mathrm{GPa}$, and Poisson constant $\nu=0.30$, and for Al-6061-T6: density $\rho=2700 \mathrm{~kg} / \mathrm{m}^{3}$, Young's modulus, $\mathrm{E}=69 \mathrm{GPa}$, and Poisson constant $\nu=0.33$.

Based on the publications of Soyama ${ }^{46}$ and Ramulu et al. ${ }^{47}$ and supported by publications for shot peening and cavitation peening ${ }^{39-42}$, the constants $\left(a, b, p_{w h, t h}\right)$ in Eq. 11a to 11d, for the increase in surface hardness and residual compressive stress as a function of the 'water -hammer pressure' $\left(p_{\mathrm{wh}}\right)$ were defined. These estimated trends are shown in Figure B-1. The numerical value are given in Table B-2. 
The threshold water-hammer pressures $\left(p_{w h, t h}\right)$ in Table B-2, using Eq. 1a and 1b, give for stainless steel AISI 316 and Al-6061-T6, respectively threshold impact velocities of $v_{d}=112 \mathrm{~m} / \mathrm{s}$ and $92 \mathrm{~m} / \mathrm{s}$.

\section{Hosted file}

Table 1.docx available at https://authorea.com/users/335126/articles/461015-fatigue-basedmodel-for-the-droplet-impingement-erosion-incubation-period-of-metallic-surfaces

\section{Hosted file}

Figure 1.docx available at https://authorea.com/users/335126/articles/461015-fatigue-basedmodel-for-the-droplet-impingement-erosion-incubation-period-of-metallic-surfaces

\section{Hosted file}

Figure 2.docx available at https://authorea.com/users/335126/articles/461015-fatigue-basedmodel-for-the-droplet-impingement-erosion-incubation-period-of-metallic-surfaces

\section{Hosted file}

Figure 3.docx available at https://authorea.com/users/335126/articles/461015-fatigue-basedmodel-for-the-droplet-impingement-erosion-incubation-period-of-metallic-surfaces

\section{Hosted file}

Figure 4.docx available at https://authorea.com/users/335126/articles/461015-fatigue-basedmodel-for-the-droplet-impingement-erosion-incubation-period-of-metallic-surfaces

\section{Hosted file}

Figure 5.docx available at https://authorea.com/users/335126/articles/461015-fatigue-basedmodel-for-the-droplet-impingement-erosion-incubation-period-of-metallic-surfaces

\section{Hosted file}

Table A-1.docx available at https://authorea.com/users/335126/articles/461015-fatigue-basedmodel-for-the-droplet-impingement-erosion-incubation-period-of-metallic-surfaces

\section{Hosted file}

Table A-2.docx available at https://authorea.com/users/335126/articles/461015-fatigue-basedmodel-for-the-droplet-impingement-erosion-incubation-period-of-metallic-surfaces

\section{Hosted file}

Figure A-1.docx available at https://authorea.com/users/335126/articles/461015-fatigue-basedmodel-for-the-droplet-impingement-erosion-incubation-period-of-metallic-surfaces

\section{Hosted file}

Table B-1.docx available at https://authorea.com/users/335126/articles/461015-fatigue-basedmodel-for-the-droplet-impingement-erosion-incubation-period-of-metallic-surfaces

\section{Hosted file}

Table B-2.docx available at https://authorea.com/users/335126/articles/461015-fatigue-basedmodel-for-the-droplet-impingement-erosion-incubation-period-of-metallic-surfaces

\section{Hosted file}

Figure B-1.docx available at https://authorea.com/users/335126/articles/461015-fatigue-basedmodel-for-the-droplet-impingement-erosion-incubation-period-of-metallic-surfaces 